\title{
DO EQUIATOMIC SOLUTIONS IN IRON POSSESS EQUAL RESISTANCES?
}

By E. D. CAMPBELL (University of Michigan).

\section{DISCUSSION.}

Professor E. D. Campbell has sent in the following reply (dated September 25, 19I8) to comments made by Mr. F. C. Thompson on his paper which appeared in the TRANSACTIONS of the Society for June, I9I7 (Vol. XII, p. 282) :-

I have been in hopes of replying to Mr. Thompson's criticism of my paper on "The Effect of Equiatomic Solutions on the Electric Resistance of Steels." For the past year, however, my time has been so fully taken up with war research work and the difficulties of administering our chemical laboratory that I have had almost to completely set aside my research work on the electrical properties of steel, and have not been able to write a reply for the Faraday Society.

Almost immediately after I received the volume of the Transactions containing Mr. Thompson's criticism I saw that Mr. Thompson's value for the specific resistance of pure iron must be very much too low. Not long afterwards I corresponded with Dr. T. D. Yensen, at that time head of the research laboratory of the Westinghouse Electric Company, who informed me that Mr. Thompson had sent him a bar of the same iron as that used in Thompson's work, and that he, Dr. Yensen, had found a value of II $\cdot 05$ microhms at $20^{\circ}$ where Thompson's results on the same metal were only $7 \cdot 77$. Yensen's values have been checked within less than $o \cdot$ Io microhms by the Bureau of Standards at Washington, and on samples sent me by Yensen of some strictly pure electrolytic iron melted in vacuo in pure magnesium oxide crucibles we agreed very closely on a value between 9.8 and 9.9 microhms measured at $20^{\circ}$. I am convinced that somewhere in his experimental work Thompson made a mistake involving an error of between 30 and 40 per cent. in his final values. If this is true, then all of the deductions he has drawn in his two publications, to which he referred me, would be rendered uncertain, if not entirely discredited.

If one takes the specific resistance values of specimens of quenched steels found by Gumlich and Goerens and quoted by Thompson, and subtracts 9.8 as the specific resistance of the pure iron solvent, it will then be found that the influence of a given per cent. of carbon on the specific resistance increases as the total per cent. of carbon increases; that is, the increase is not a function of the total atomic concentration, but is a function of the molecular concentration, as was maintained in my paper. 
Mr. Thompson's last inference, that my steel bars were not properly protected from oxidation during the long annealing, was quite unfounded. The bars were very carefully packed in such a way as to avoid any decarburization.

Dr. F. C. Thompson (communication dated December 6, 1918) : With regard to the resistance of pure iron and Dr. Yensen's value for the sample I sent him, the fact that he gets such a much higher value than mine is disconcerting. It must be borne in mind, however, as I pointed out to Dr. Yensen when I forwarded the material, that what I sent on was similar to that which I used, but not the same. The actual samples were subsequently made into tensile test pieces and broken.

To leave things as they are at present is rather a pity, but at present I am quite unable to return to the subject. When later an opportunity arises to do so, I shall take it at once. 